\title{
LVI. On the sea-waves connected with the Japanese earthquake of June 15, 1896
}

\section{Charles Davison Sc.D. F.G.S.}

To cite this article: Charles Davison Sc.D. F.G.S. (1900) LVI. On the sea-waves connected with the Japanese earthquake of June 15, 1896 , Philosophical Magazine Series 5, 50:307, 579-584, DOI: $10.1080 / 14786440009463948$

To link to this article: http://dx.doi.org/10.1080/14786440009463948

册 Published online: 21 Apr 2009.

Submit your article to this journal $\lceil\pi$

Џ Article views: 3

Q View related articles $\asymp$ 
lines per sq.. cm. per ampere. $B_{y}$ opening $\mathrm{K}$ a throw was obtained first with the needle exactly in the coil plane (normal throw), next with the needle turned out of the coil plane by a small angle $\theta *$ (abnormal throw). The difference between these throws expressed as a percentage of the normal throw and plotted against the current I flowing round KLB at the moment of break gave one of the points of fig. 2 ; and the other points corresponding to otber values of $\theta$ and of I were obtained in like manner.

On examination it is seen that the whole of these result: can be gathered up into the formula

$$
\left.\begin{array}{l}
\begin{array}{l}
\text { Percentage excess of Abnormal } \\
\text { over Normal throw }
\end{array}
\end{array}\right\}=330 \theta \mathrm{I}^{2}, \quad \text {. }
$$

where $\theta$ is in degrees and $I$ in amperes, $\theta$ being regarded as positive when the initial displacement of the needle is in the same direction as the throw, but negative when in the opposite direction.

From a comparison of $(4 b)$ with $(4 a)$ it is to be inferred that the induction-coefficient of the needle of the particular galvanometer used was $\cdot 0015$, a ralue not very different from that previously adopted for $\alpha$.

Owens College, Manchester.

LVI. On the Sea-Waves connected with the Japanese Earthyualie of June 15, 1896. By' Charles Davison, Sc.I). F.G.S.†

[Plate V.]

THE Japanese earthquake of June 15, 1896, is one that deserves to have its history fully written. So far, it has only been briefly referred to in a few papers $\ddagger$, with the

* In reality it was the galvanometer-coil that was turned, the needle being left in a fixed plane and under a fixed controlling tield; but it is more convenient to speak, as abore, of the displacement of the needle relatively to the coil thought of as fixed.

$\rightarrow$ Communicated by the Author.

$\ddagger$ J. Milne, "The Grea: Sea-W aves in Japan." Geogr. Journ, vol. viii. (1896, pp. $157-160$.

J. Nilne, ["On the Sea-Waves and Earthquakes of June 15, 1896, in North Japan "]. Brit. Assoc. 'Keport (1897), pp. 25-31.

F. Omori and K. Hirata. "Earthquake Measurement at Miyako." Iourn. Sci. Coll., Imp. Univ., Tokyo, vol. xi. (1899), pp. 161-195, especialiy pp. 164-166, and figs. 1 and 8 .

"The Great Seismic Wave in Japan." 'Nature,' vol. lir.. (1890), pp. $449-450$.

"'The Great Dieaster in Japan, June 15th, 1896." (A. series of articles reprinted from the Japanese Gazette, Yoliohama.) 
exception of a report presented to the Japanese Government, of which no adequate summary has, I believe, appeared in any European language. In the present paper, I shall therefore confine myself to considering the propagation of the seawaves in an easterly direction, one of $m y$ objects being to compare the mean depth of the ocean as obtained by soundings with that obtained from the formula usually employed

$$
\sqrt{ }(g \mathrm{H})=\mathrm{V},
$$

where $\mathrm{H}$ is the uniform depth of the ocean in which waves would travel with the same mean velocity $\mathrm{V}$ as that of the seismic sea-waves. I have shown in a previous paper* that the value so found must be considerably less than the true mean depth; the calculated value in a particular case considered being 1900 fathoms instead of 2420 fathoms, i.e. about $\frac{4}{5}$ of the real value.

In tig. 1 are shown the parts of Central and Northern Japan that were chiefly affected by the earthquake, the town of Kamaishi being practically destroyed by the sea-waves. The continuous curves represent isoseismal lines. Within the eurve marked 2, the shock uas "weak," the motion being well-pronounced, but not sufficiently severe to cause general alarm; between the two curves 1 and 2 the shock was "slight," and only just strong enough to be felt. The dotted curves are sub-ocennic contour-lines, the figures anmexed to each giving the depth in fathoms. According to $\mathrm{Mr}$. 'T. Iki, the epicentre was situated in lat. $39^{\circ} \mathrm{N}$. and long. $144^{\circ} 30^{\prime}$ E., or about $240 \mathrm{~km}$. E.S.E. of Miyako. It is indicated on the map by a cross, and lies at a depth of t000 fathoms near the foot of the western slope of the Tuscaroora Deep.

Prof. Omori informs me that the surface-velocity of the earthquake-waves within the disturbed area was about $2 \cdot 7 \mathrm{~km}$. per second, and, as the time of occurrence at Miyako was 7h. $32 \mathrm{~m} .30 \mathrm{~s}$. P.M. (mean time of $135^{\circ}$ E.), this would give $7 \mathrm{~h} .31 \mathrm{~m}$. (or $10 \mathrm{~h} .31 \mathrm{~m}$. A.M., G.M.T.) as the approximate time at the epicentre. This result is probably correct to within a minute.

'Though I made inquiries at all the harbours known to me where self-recording tide-gauges are established, records of the sea-waves appear to have been obtained at only two stations, namely, Honolulu and Sausalito (San Francisco Bay). Copies of these records are given on a reduced scale in fig. 2 and Plate V. For these and for other info:mation given

* Phil. Mag. vol, xliii. (1897), pp. 33-36. 
below, I am indebted to the kindness of Prof. W. D. Alexander, Surveyor-General of the (then) Hawaiian Government Survey, of Mr. T. R. Walker, British Vice-Consul at Honolulu, and of Mr. W. W. Duffield, Superintendent of the U.S. Coast and Geodetic Survey.

Fig. 1.

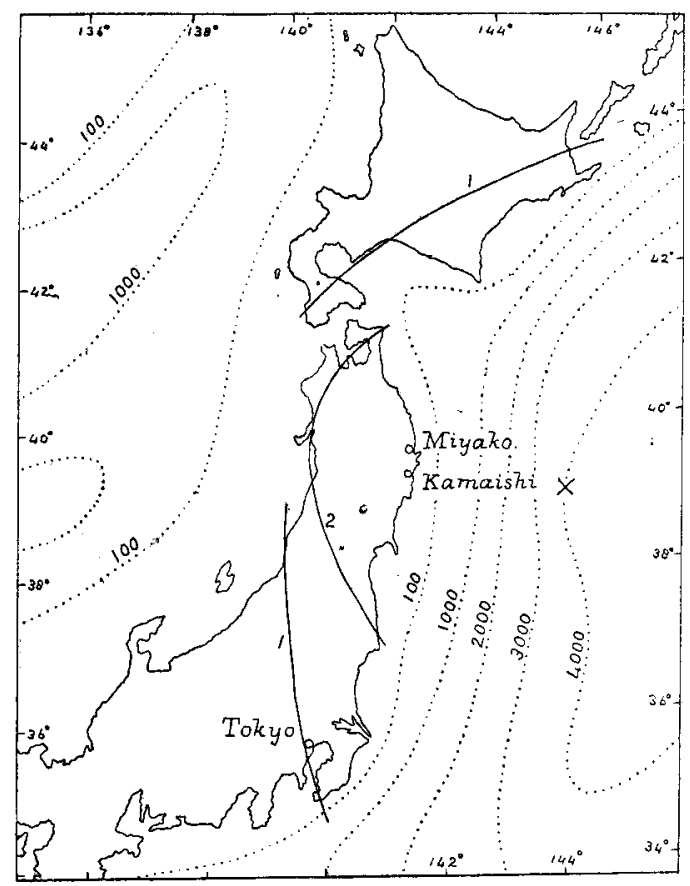

Honolulu (lat. $21^{\circ} 5^{\prime}$ N., long. $158^{\circ} 0^{\prime}$ W.).-The tidegauge at this station is one of the Stierle pattern and has been in operation since 1891. The tide-gauge house is on the Esplanade, north-east of the Oceanic Co.'s whart, where a well was sunk in solid ground to a point below the lowest iides, and connected with the sea by a large horizontal pipe. The scale of the diagram is one inch per hour for the horizontal coordinate, and one inch per foot for vertical displacement. The time is mean local time.

Prof. Alexander writes that " the earthquake-waves were very slightly felt on Oahu and Maui, were more pronounced at Kauai, and reached their maximum on the north coast of Hawaii. The sea rose at Kailua and Keauhou in Kona, Hawaii, eight feet above ordinary high-wats:r mark, flooding 


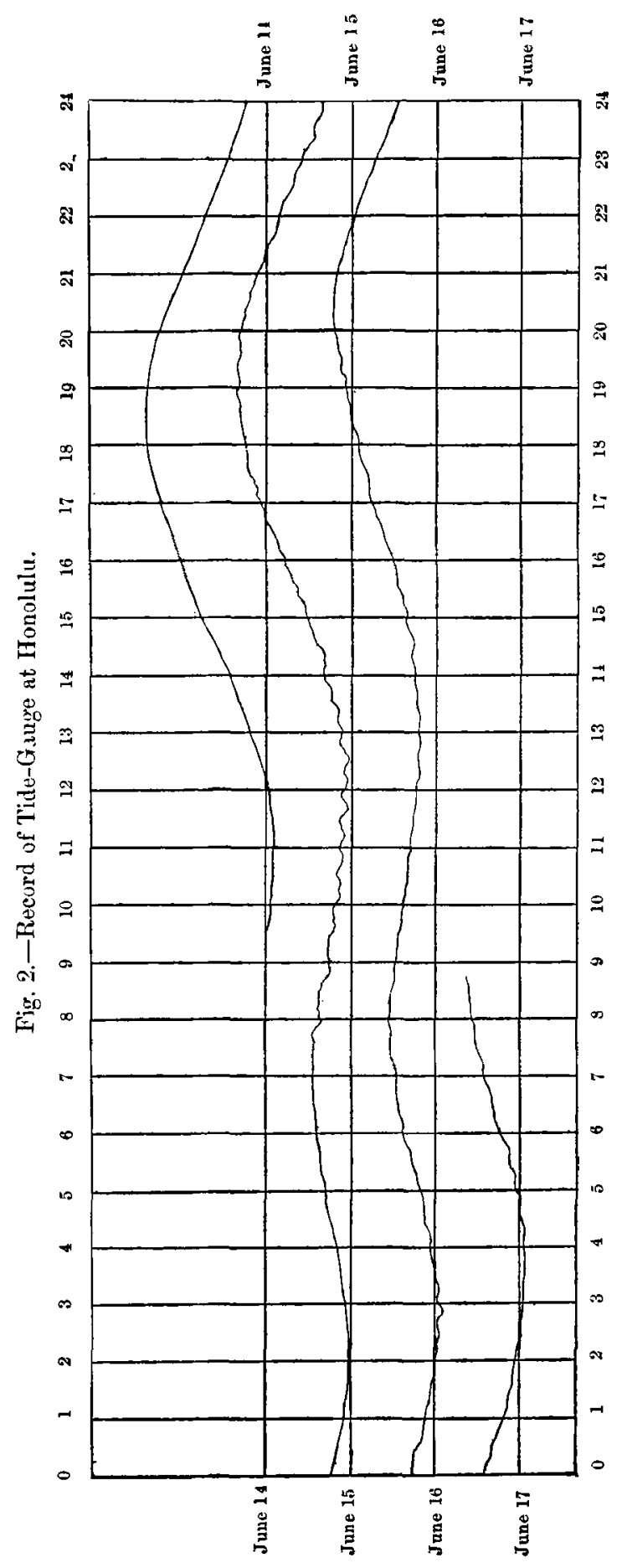


On Sea-Waves connected with a Japanese Earthquake. 583

houses, throwing down stone walls, \&c. It was reported from there that an extraordinary fall or recession of the sea preceded the greatest wave. No accurate observations seem to have been made in those localities of the times and the number of the prominent waves."

The record at first shows a steady rise and fall of the water; and it is not until $7 \mathrm{~h} .37 \mathrm{~m}$. A.M. on June 15 that any change occurs. There is then a small rise of about $\frac{3}{4}$ of an inch, the first crest reaching the gauge at $7 \mathrm{~h} .43 \mathrm{~m}$. (i. e. at $6 \mathrm{~h} .15 \mathrm{~m}$. P.M., G.M.T.). For about two hours this motion is somewhat irregular; but between $9 \mathrm{~h} .55 \mathrm{~m}$. A.M. and $5 \mathrm{~h} .8 \mathrm{~m}$. P.M. on June 15 there is a group of 17 waves with an a verage period of $25 \frac{1}{2}$ minutes. 'The waves are all sinall; they are most marked between $9 \mathrm{~h} .55 \mathrm{~m}$. A.M. and $1 \mathrm{~h} .40 \mathrm{~m}$. r.M. ; and even then the mean distance between crest and hollow of snccessive waves is only $1 \cdot 2$ inches. The copy of the record closes at 8 P.M. on June 17, when the surface of the water show: signs of returning to its normal steadiness.

The distance between the epicentre and Honolulu, measurel along a great circle, is 3591 miles ; and, the timeinterval being $7 \mathrm{~h} .44 \mathrm{~m}$., it follows that the mean velocity was 681 feet per second. If the ocean were of uniform depth between the two points, the depth corresponding to this mean velocity would be 14,492 feet.

Sausalito (lat. $37^{\circ} 51^{\prime}$ N., long. $122^{\circ} 29^{\prime}$ W.).-Sausalito lies at the entrance to San Francisco Bay. At the time of tho earthquake, the gauge here was the only automatic gauge in operation on the Pacific coast of the United States. 'The scale is .93 inch per hour for the horizontal coordinate (measured from the copy of the record), and 1 inch per foot for verticul displacement. The time is the Pacific standard, that of the 120th meridian west of Greenwich.

In this, as in the Honolulu record, the first evidence of any change is a rise (of 3.7 inches) in the level of the water *, beginning at $12 \mathrm{~h} .53 \mathrm{~m}$. P.M. on June 15 , the first crest reaching the gauge at $1 \mathrm{~h} .5 \mathrm{~m}$. P.M. (i.e. at 9 h. 5 m. P.M. G.M.T.). During the first two hours, the waves are larger and of longer period than those which follow, the chief movement being between $1 \mathrm{~h} .30 \mathrm{~m}$. and $1 \mathrm{~h} .45 \mathrm{~m}$. P.M., when the water rose $6 \cdot 8$ inches and fell $2 \cdot 2$ inches. After this, they become more regular. Between 3 and 6 P.M. there are 30 waves, with an average period of 6 minutes and a mean distance between

- It should be noticed that at two Japanese stations, Ayuks,wa and Hanasaki-mura, the first movemeat was a fall in the level of the water. Nature, vol. liv. p. 449 (1896). 
crest and hollow of successive waves of 1.5 inch. At 1 A.M. on June 17, when the copy of the record ends, there were still very distinct signs of movement due to the Japanese earthquake.

The distance from the epicentre to Satisalito is 4787 miles, the time-interval is $10 \mathrm{~h} .34 \mathrm{~m}$., and the mean velocity between the two places 6144 feet per second. On the same assumption as before, the mean depth of the ocean would be 13,778 feet.

Mean Depth of Pacific Ocean as ascertained from Soundings. -I have estimated roughly the depth of the ocean along the two lines from the epicentre to Honolulu and Sausalito, making use for the purpose of the Physical Chart of the World which accompanies the "Narrative" of the Voyage of H.M.S. 'Challenger'"

The epicentre-Honolulu line traverses a part of the ocean whose depth is very variable: indeed, the long chain of islands of which the Hawaiian Islands form the eastern end almost lies along the great circle joining the two places. Along the most direst course which the wave might take, the mean depth is about 13.500 feet. But along a very slight deviation from this line the depth is much greater ; and it is probable that the earliest, waves which reached Honolulu would take some such course. It is therefore useless to compare this result witb that abtained above from the velocity of: the seismite sea-waye.

Along the epicentre-Sausalito line the conditions are very different. The great circle joining the two places is entirely tree from islands, and crosses the sub-oceanic contour-lines approximately at right angles. The mean depth along this line is more than 17,000 feet, while that obtained from the formula is 13,778 feet, or about $\frac{4}{5}$ of the measured value.

LVII. On the Law of Partition of Energy. By S. H. Burbury, M.A., F.R.S. $\dagger^{\prime}$

1. IF a material system be defined by the generalized coordinates $q_{1} \ldots q_{n}$ with the corresponding momenta $p_{1} \ldots p_{n}$, so that the kinetic energy is $\frac{1}{2}\left(p_{1} \dot{q}_{1}+\ldots+p_{n} \dot{q}_{n}\right)$, the law of partition of energy is the relation between the several products $p \dot{q}$ on average of time when the system is in stationary motion. The law of equal partition asserts that, under certain conditions to be investigated, $\overline{p_{1} \dot{q}_{1}}=\overline{p_{2} \dot{q}_{2}}=\& \mathrm{c}$.

* Report on the Scientific Results of the Voyage of II.M.S. ' Challenger,' Narrative, vol. i. pt. 1 (1885).

$f$ Communicated by the Author. 
Record of TIDE-GaUge at SaUsalito (SAN FRAnCISCO Bay).

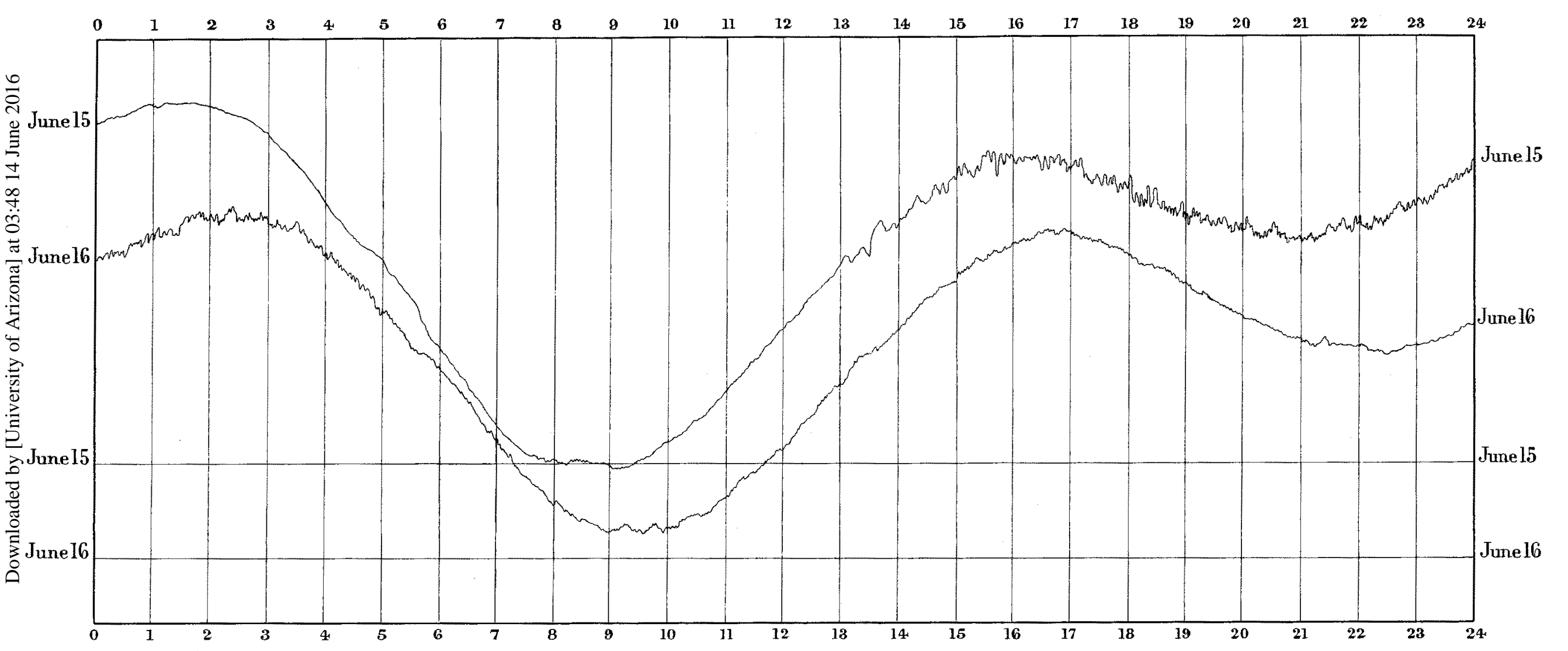

